\title{
Translations of Soviet Publications
}

G ROWING INTEREST in developments within the Soviet Union in the past few years has stimulated unprecedented American desire to gain access to information printed in Soviet publications. The sense of urgency caused by Sputnik I caused a public outcry for large-scale translations of Soviet scientific and technical publications. The flurry of demand resulted in the establishment of several programs for translating Soviet scientific and technical journals from cover to cover. Yet very little discussion has appeared in print about several aspects of the problem of translating which make it a more complicated matter than it appears to be at first glance.

A good deal of confusion seems to surround the question of translations from the Russian. On the one hand there has been a loud demand for them. On the other hand actual use of those available has proved to be rather small. Librarians who more than anyone have to face daily demands for literature and at the same time to plan for the future are caught in the middle and are also distressed at the new and heavy burden threatening their budgets. The purpose of this article is to try to identify the principal aspects of the problem and to unravel some of the elements of confusion. If this could be done, rational planning would be easier.

Translation is a more serious problem for scientists and engineers than for social scientists and humanists. Printed material which is significant for scientists and engineers may appear in any language; to follow developments in

Mr. Ruggles is Vice-President, Council on Library Resources, Inc. their special fields of interest scientists and engineers must either be polyglot or find some common means of communication. Social scientists and humanists, however, are much more inclined to specialize in geographical areas. Consequently the Russian language is only incidental to the study of natural science and technology, while it is likely to be an essential tool to any social scientist or humanist dealing with Russian affairs, and therefore a prerequisite to the pursuit of his studies which he will have acquired as a part of his training. On the other hand, social scientists and, to a lesser extent, humanists who are not specialists in Eastern Europe tend to be less interested in the scholarly work of their Soviet counterparts than are scientists and engineers. This difference arises from the fact that the Communist Party cannot permit objectivity and limits creative thought in the social sciences, but allows considerable latitude in those sciences which do not deal with human behavior. Therefore the work of Soviet specialists in the former fields often has little intrinsic value (although as a reflection of Soviet policy such material can be very useful) while Soviet work in the natural sciences and technology can be extremely worthwhile. These circumstances combined lead to the following situation: a large proportion of all U.S. scientists and engineers are interested in the content of Soviet publication in their fields, but only a small percentage of this large group can read Russian; conversely only a small proportion of social scientists and humanists are interested in following Soviet developments in their disciplines, but of those who are interested in get- 
ting at the content of Soviet publications a very high percentage can read Russian. ${ }^{1}$

Despite the above generalizations which indicate an apparent greater need of natural scientists and engineers for translations from the Russian, there is nevertheless a rather heavy demand for translations on the part of faculty members and researchers in other fields. This demand is made particularly by those conducting undergraduate courses and by those not concentrating on East European area studies. The need is felt particularly acute in the fields of political science, belles-lettres, history, and economics. The apparent contradiction between this statement and the observation in the preceding paragraph is due to the fact that the demand for translations is more often expressed by generalists rather than by subject specialists. That is, a teacher giving a survey course on comparative government is likely to want to read translated material from Soviet books, periodicals, and newspapers whereas a specialist on Western European parliamentary government is less likely to be interested in consulting the works of Soviet specialists in his field. The interest of journalists and publicists in Soviet materials in translation also creates a certain demand for translations. University faculty members need translated anthologies of Russian and East European literature, source books in history and political science, and full translations of Russian and Soviet classics in each of these fields. With respect to the latter, many faculty members are grateful for the translation program conducted by the American Council of Learned Societies for a few years after the war and would like to see it resumed. There is widespread praise for the Current $D i$ gest of the Soviet Press, and desire that its coverage be expanded.

It appears that the needs of scientists

\footnotetext{
1 The same situation applies to the publications of other countries within the Soviet bloc.
}

and engineers are currently being met much more adequately than the needs of those engaged in social studies. Various official agencies subsidize or otherwise assist translation and abstracting services for scientists and engineers. This effort is reflected by the list of the principal sources of translations as well as the list of the scientific and technical journals currently translated from cover to cover which appear in each issue of Technical Translations, an abstract journal of translated articles published twice monthly by the Office of Technical Services of the U.S. Department of Commerce.

Several organizations, both academic and official, are also financing, sponsoring, or otherwise assisting research on mechanical translation. In all probability mechanical translation will someday solve many aspects of the kind of problem now facing the United States. But the state of the art in this field is at present not sufficiently advanced to offer any hope of assistance in the immediate crisis. Therefore, this fascinating field in which the knowledge and skills of linguist and mathematician are jointly engaged can receive only passing mention in any paper on practical and present problems of translation.

While the work being accomplished by various organizations concerned with translating Russian materials is impressive, the potential users (as represented particularly by scientists and engineers) are, nevertheless, far from content. Their appetites appear to be insatiable, although, as we shall see, the demand is more intensive (representing a relatively small group) than extensive.

The obvious need and the heavy demand for translations have tended to obscure some basic problems in gaining access to Soviet data which translations cannot solve, as well as some other serious problems affecting the process of translation itself.

The most serious literature problem confronting scholars in all fields today 
is the mass of material published. Large scale translation of Soviet publications would add to the already unmanageable volume of printed matter which scholars presumably must peruse in order to keep up with development in their fields. Fragmentary evidence that is available indeed casts doubt on the assumption that a large scale program of translations from the Russian would be adequately exploited by those for whom it was intended, or possibly even by many who now clamor for it. As of June 1959 there were approximately seventy-five Soviet scientific and technical journals being translated into English (about 90 per cent in the U.S., the remainder in Great Britain). Not one of these translated versions had a circulation of as much as 1,000, and the average number of subscribers was between 200 and 300. Possibly real consumer demand might not justify investing more valuable man-years and thousands of dollars in a product which thus far may have been influenced more by newspaper headlines (especially in the few weeks between the launching of Sputnik I and Explorer I) than by actual requirements of potential users. As this is written only one scientific study exists which contributes reliable data on actual demand by scientists for translations from the Russian language. Herner ${ }^{2}$ made an interview study in 1956 and 1957 of 500 medical scientists in fifty-nine medical research organizations in six American cities with the object of discovering their need for information from Soviet publications and the best means for meeting the need. He found that whereas only 6 per cent of the group (i.e., thirty) could read Russian, nearly one half (240) had sought or obtained Soviet information in the previous six months. Of these, fifty-eight had followed Soviet journals with some frequency, but of these fifty-eight only eight saw them in

\footnotetext{
2 Saul Herner, "American Use of Soviet Medical Research," Science, CXXVIII (1958), 9-15.
}

translated form. Herner also discovered that while 6 per cent of his sample could read Russian, only 3 per cent had read any Russian material in the original language within the preceding six months. The primary means used by the respondents for obtaining information from Soviet sources was through indexing and abstracting publications. The second most generally used method was through second-hand reports of Soviet developments which appeared in English language studies and reviews. These data would seem to indicate that even when means were available for getting access to the full text (either by knowledge of the Russian language or by use of translations) the researchers preferred short cuts.

The Herner study asked the medical scientists interviewed to recommend methods whereby accessibility to Soviet materials might be increased. The method most frequently suggested was that existing indexing and abstracting publications increase their coverage of Soviet literature. Some, though considerably fewer, suggested dissemination of translated tables of contents of current Soviet medical publications. (Most Soviet scholarly journals in all fields now include tables of contents and sometimes abstracts in the English language). When asked specifically about translations, the largest segment of the group interviewed recommended "facilities for having translations made on request, with the individual scientist ordering translations of specific items as he needs them." This suggestion corresponds very closely with statements made by several scientists and engineers interviewed by the present writer: they said that the best means they had found to get access to Soviet literature was to have on their staff a member who knew both the Russian language and the subject matter of their specialization, and whose duty was to disseminate to the others the relevant and important Soviet data he found. This person would syste- 
matically peruse Soviet publications, bring relevant data to the attention of his colleagues and, when appropriate, translate portions of articles or entire articles.

The difficulty in finding competent translators is in fact one of the serious obstacles to any large scale program of cover-to-cover translation. A translator must know not only the Russian language but the subject matter as well. Most people possessing these two skills much prefer to spend their efforts in research rather than translating.

Even the best translations are still inadequate as means of communicating the ideas of Soviet researchers to their American counterparts. Nouns of the scientific and technical vocabularies of all IndoEuropean languages tend to have common antecedents in Greek and Latin and the meaning is likely to be precise and equivalent in all languages. Such equivalence is much less likely to occur, however, with adjectives and still less with verbs and adverbs. Yet these parts of speech define and indicate what the researcher believes is happening to the things designated by the nouns. Even very good translations, therefore, must necessarily fail to communicate some nuances of meaning and to reveal differences of national style in performing research and experimentation.

Translations fail completely to serve another very important means of communication among scientists: interchange of ideas by tête-à-tête conversations. Incidentally this fact tends to limit the circle of those scholars who have opportunity to communicate directly with their counterparts in other countries, because scientific organizations are inclined to send to international meetings representatives who can speak foreign languages.

Even if cover-to-cover translation of all important Soviet publications were an adequate solution to America's need for access to Soviet-produced data, it would be economically unfeasible. By rough estimate approximately one million pages of Soviet text which would be really interesting to American scholars are produced each year in the fields of science and technology alone. By a more accurate estimate, it costs about twentyfive dollars a page ${ }^{3}$ to produce translations of Soviet material (from the receipt by air mail of the original Soviet publication to the deposit of the translated version in the mail box of the recipient). With $\$ 25,000,000$ annually it would be possible to train, each year, between 75 ,000 and 100,000 Americans to read the Russian language.

Libraries cannot afford to purchase all of the available translations of Soviet scientific and technical publications which are now available-and which hardly scratch the surface of Soviet output-even at the relatively low prices made possible by subsidies. Most of the seventy-five journals now being translated cover-to-cover are heavily subsidized: the average subscription price is about one-tenth of the actual cost of production, and even lower rates are granted libraries by several of the journals. Yet the total subscription cost of these journals, despite subsidies and special library rates, is well over $\$ 2,500$ annually. This figure represents about onehalf of the total annual budget for the purchase of all East European (not only Russian) publications in the original language of any one of the majority of our twenty largest university libraries, one-sixth of the same category in the budget of the four largest American university libraries, and one-eighth the annual expenditure for Russian publications of the Library of Congress.

Some libraries, once they have subscribed to English-language editions of Soviet periodicals, cease their subscrip-

\footnotetext{
3 One element in this high cost is the number of man hours required for translation-a necessarily slow process. This expenditure of human time presents an in ess. This expenditure of human time presents an ineluctable choice: either translation of the most impor or their cost must be very high.
} 
tions to the original Russian language periodicals. This appears to be a retrogressive policy, depriving both those who can read the original version and those who wish to learn Russian of the opportunity of getting first-hand access to Soviet information. Several faculty members, both in the exact and the social sciences, emphasize the educative value of a research library's possession of materials in the Russian language which would stimulate and challenge scholars to learn enough Russian to extract value from them. Librarians interested in the continuity of periodical files are also likely to calculate that original Russian publications are obviously more stable than translated versions and will not permit subscription to or purchase of a translated version of a Russian publication to supersede the acquisition of the original except in special circumstances. This wise, conservative policy, however, seriously affects costs of acquisition.

One specific conclusion seems to emerge from the above: large scale translation of Soviet materials is highly uneconomical from several points of view.

Nearly total dependence on translations, it would therefore seem, must be considered a stopgap measure, pending an inevitable increase in the number of scholars in all fields who will be able to read and speak Russian. The long-range solution lies in the introduction of Russian language courses into high school and college curricula. Experience in a few scattered schools indicates that parents and students alike are aware of the growing importance of Russian in the general cultural picture. Most of the courses offered thus far have been quickly oversubscribed and are already suffering from a shortage of qualified teachers.

Shorter-range measures are also feasible, and can be carried out concurrently with the longer-range program. The most promising solution seems to be accelerated courses in scientific Russian which have mushroomed in many parts of the country in the last few years. These are either offered by a college or university as part of the regular curriculum, or contracted for by an individual research organization, or conducted on a purely private basis by an interested Russian specialist. Typically, the course runs one or, less often, two semesters, concentrates exclusively on reading proficiency, and specializes in the terminology of one subject field. Industrial firms often carry the cost of the instruction and release their employees from extra duties_-such as business trips-during the four-month course. The reported results have been encouraging: in twelve to fifteen sessions scientists have learned to read, with the aid of a dictionary, Russian articles in their fields of specialization.

Most universities require reading knowledge of two foreign languages by candidates for higher degrees. French and German are still being given preference over other languages, probably because of strong tradition and because of the frequently privileged position of the French and German faculty members in the departments of language. Recently, however, several institutions have permitted Russian to be one of the required languages - a trend which obviously will help to solve the problem of access to Soviet-published information.

Several major research libraries have made dents in the language barrier by maintaining a roster of competent translators to whom readers, once they have found needed material with the help of library's reference staff, are referred. The fee for translation is paid, of course, by the reader.

Very often when translations are made on special request or for limited groups, the translated material remains in the files of a few individuals. Thus the same material may be translated by two or more persons independently, or at least translations which would probably be used by many people if available to them 
never come to their attention. Special efforts are now being made to reduce such duplication of effort or inadequate use of available resources. The Office of Technical Services of the Department of Commerce and the John Crerar Translation Pool in Chicago are devoting particular attention to this problem.

It would appear from the above that translation from the Russian is not a simple question and that demand for translations cannot be accepted without question by those responsible for or affected by the costs involved. ${ }^{4}$ Officials of those agencies which are concerned with improving access of American scholars to Soviet publications are aware of the problems and limitations of translations,

4 Much informative data on translations and other means of obtaining. Soviet scientific and technical information appears in Part 2 of the Hearings on the 4039 ) held on June 25 and 26,1958 , before a subcommittee of the Committee on Government Operations of mittee of the Committee on Government Operations of
the United States Senate. Officials of the principal U.S. government agencies which deal with bibliographical problems in the fields of science and technology testified on this occasion and inserted into the record much valuable additional information. and have been planning programs for better approaches to the problem accordingly.

We seem to be entering a period similar to the latter part of the nineteenth century when American scientists began to realize that foreign science and technology (particularly German) was in an advanced state, and made the effort to learn the languages-especially German - which would enable them to be informed about developments abroad. One difference is that in the middle of the twentieth century the recognition of the advanced state of Soviet science has lagged further behind fact than it did in the nineteenth century with respect to Western European science and technology. Another difference is the urgency of time required to overcome the lag. The recovery of lost time will be quicker once the real nature of the many sided problem of getting access to Soviet printed data is fully understood.

\section{ACRL Grants for Research}

From funds given by the United States Steel Foundation to support ACRL's Grants Program for 1959-60 the ACRL Grants Committee will, in addition to making seventy-five to a hundred sub-grants to college and university libraries, make a limited number of grants to individual librarians for research projects directly concerned with college and university librarianship.

Applications should be made by letter. (No forms are required.) Amounts up to $\$ 1,000$ may be requested. Letters of application should state succinctly the purpose of the project, its present state of development, its proposed date of completion, the use planned for the funds granted, and the reasons why funds from outside the applicant's own institution are sought. Applications must be received no later than October 16. They should be mailed to Richard Harwell, Executive Secretary ACRL, 50 East Huron Street, Chicago 11, Illinois.

In its first two years (1955) and 1956) the ACRL Grants Program included research grants to individuals. These grants have been at least partially responsible for such publications as Patricia Knapp's College Teaching and the College Library, ALA's Catalog Use Study, and a number of worthwhile articles and reports. 